responsible for the increase in incidence of gastroschisis. Further structured prospective studies of pregnancies complicated by gastroschisis are required to define precise risk factors so that preventive measures may be taken. While this can be done on a relatively small scale in individual units, there is no doubt that countrywide epidemiological data would also be very helpful. It would seem that the statutory reporting system in England and Wales is currently inadequate for this purpose, and the development of more local (or perhaps national) congenital malformation registers such as exist in North West Thames region and some other regions should be encouraged.

LYN CHITTY

Consultant in genetics and fetal medicine

JOSEPH ISKAROS

Research registrar

Fetal Medicine Unit, University College Hospital,

London WC1E 6AU
1 Tan KH, Kilby MD, Whittle MJ, Beattie BR, Booth IW, Botting BJ. Congenital anterior abdominal wall defects in England and Wales between 1987-1993. BMf 1996;313: 903-6.

2 Crawford RAF, Ryan G, Wright VM, Rodeck CH. The importance of serial biophysical assessment of fetal wellbeing in gastroschisis. Br $\mathcal{O}$ Obstet Gynaecol 1992;99:899-902.

3 Iskaros J, Morrison JJ, Chitty LS, Rodeck CH. Epidemiological and sonographic features of fetal gastroschisis and neonatal outcome. Brf Obstet Gynaecol 1996;103:845.

4 Drongowski RA, Kendall Smith R, Coran AG, Klein MD. Contribution of demographic and environmental factors to the etiology of gastroschisis: a hypothesis. Fetal Diagn Ther 1991;6:14-27.

5 Morrow RJ, Whittle MJ, McNay MB, Raine PAM, Gibson MM, Crossley J. Prenatal diagnosis and management of anterior abdominal wall defects in the west of Scotland. Prenat Diagn 1993;13:111-5.

6 Di Lorenzo M, Yazbeck S, Ducharrne JC. Gastroschisis: a 15-year experience. $f$ Pediatr Surg 1987;22:710-2.

7 Chitty LS. Ultrasound screening for fetal abnormalities. Prenat Diagn 1995;15:1241-57.

8 Lafferty PM, Emmerson AJ, Fleming PJ, Frank JD, Noblett HR. Anterior abdominal wall defects. Arch Dis Child 1989;64:1029-31.

9 Nicholls G, Upadhyaya V, Gornall P, Buick RG, Corkery JJ. Is specialist centre delivery of gasNicholls G, Upadhyaya V, Gornall P, Buick RG, Cork
troschisis beneficial? Arch Dis Child 1993;69:71-3.

10 Torfs CP, Velie EM, Oechsli FW, Bateson TF, Curry CJR. A population-based study of gastroTorfs CP, Velie EM, Oechsli FW, Bateson TF, Curry CJR. A population-based study of
schisis: demographic, pregnancy and lifestyle risk factors. Teratology 1994;60:44-53.

11 Hume FH, Gingras JL, Martin LS, Hertzberg BS, O'Donnell K, Killam AP. Ultrasound diagnosis of fetal anomalies associated with in utero cocaine exposure: further support for cocaine-induced vascular disruption teratogenesis. Fetal Diagn Ther 1994;9:239-45.

12 Hoyme HE, Higginbottom MC, Jones KL. The vascular pathogenesis of gastroschisis: Intrauterine interruption of the omphalomesenteric artery. $\mathcal{F}$ Pediatr 1981;98:228-31.

13 Volpe JJ. Effect of cocaine on the fetus. N Engl F Med 1992;327:399-405.

\title{
Intracoronary stents
}

\author{
Reducing restenosis after angioplasty
}

Coronary angioplasty has become an accepted treatment for coronary disease, with over 13000 procedures performed in Britain in 1995 (410 000 in the United States). During the 1980 s the overall primary success rate of angioplasty was $90 \%$, with complications such as myocardial infarction, emergency surgery, and death occurring in up to $0.9 \%, 3.2 \%$, and $1.2 \%$ of cases respectively, depending on the extent of coronary disease. ${ }^{1}$ However, even with recent improvements in angioplasty technology, percutaneous revascularisation techniques have been limited by restenosis, predominantly through neointimal hyperplasia, but also through vessel shrinkage (adverse remodelling). ${ }^{2}$ Angiographic restenosis occurs in $30-50 \%$ of cases by six months' follow up, with clinical (symptomatic) restenosis in most of these cases. ${ }^{1}$ With no pharmacological treatment consistently reducing the restenosis rate in randomised studies, there has been an increased need for reintervention with further angioplasty or bypass surgery in $44 \%$ over the first three years of follow up, offsetting the initial savings in cost and morbidity. ${ }^{3}$ Intracoronary stents, deployed by balloon dilatation at the site of coronary stenoses, were first developed as a mechanical means of preventing restenosis. They also allowed "bailout" from acute closure $^{4}$ (avoiding myocardial injury or emergency surgery) with preserved vessel patency at angiographic follow up. ${ }^{45}$

Intracoronary stents are deployed by balloon dilatation at the site of coronary stenoses. Balloon angioplasty works by a combination of stretching the vessel wall and rupturing the plaque. Depending on the complexity of the lesion, plaque rupture results in dissection of the wall to differing degrees in most cases. In the past, acute or threatened stenoses were treated either by dilatation with a perfusion balloon catheter or by emergency surgery, with high rates of myocardial injury and occasional deaths.

The use of intracoronary stents in both elective and emergency situations has reduced the rates of acute stenosis, emergency surgery, and myocardial infarction, as well as reducing the rate of restenosis by a third. ${ }^{6} 7$ Early studies reported unacceptably high rates of stent thrombosis, ${ }^{45}$ necessitating an aggressive antiplatelet or antithrombotic strategy. ${ }^{89}$ Improved stent design and deployment has reduced the incidence of stent thrombosis, which occurred over the first 10 days after angioplasty in up to $18 \%$ of patients. $^{89}$ This occurred particularly where the stent was deployed in a bailout situation, although very rarely in vessels more than $3 \mathrm{~mm}$ in diameter.

An aggressive antithrombotic strategy was associated with vascular and bleeding complications in up to $15 \%$ of cases. ${ }^{8-10}$ Recent trials have suggested that formal anticoagulation is no longer necessary: the antiplatelet drug ticlopidine, along with aspirin, can be used to reduce the risk of subacute thrombosis. ${ }^{11-13}$ Use of ticlopidine is restricted in some countries because of rare reports of reversible neutropenia. Thus, until recently, stenting required anticoagulation with intravenous heparin for up to 96 hours after deployment. One multicentre study of 246 patients who had undergone stenting confirmed the safety of using aspirin, ticlopidine, and 48 hours of intravenous heparin followed by low molecular weight heparin for one month. ${ }^{12}$ The rate of stent thrombosis was as low as $1.2 \%$, even though $12 \%$ were bailout stents. Vascular complications occurred in $11 \%$ of cases. Subsequent reports from this registry of 1183 patients receiving aspirin and ticlopidine alone have confirmed a rate of stent thrombosis of $1.2 \%$ with no vascular complications.

Initial observations suggested that in most patients the stent failed to expand completely after deployment. ${ }^{14}$ As this may not be apparent at angiography, intravascular ultrasound has been used to guide adequate stent deployment with high pressure dilatation (more than 12 atmospheres) and larger balloon sizes to improve expansion and reduce the need for formal anticoagulation. In one study of $\mathbf{4 5 2}$ stented lesions, subacute thrombosis occurred in only $0.9 \%$ of lesions. ${ }^{11}$ A comparison of aspirin alone against aspirin and ticlopidine in 226 patients undergoing stent implantation guided by ultrasound showed no difference in the rate of stent thrombosis $(2.9 \% v 0.8 \%)$ or in major clinical events, confirming an advantage over studies also using warfarin. ${ }^{13}$ The recent Benestent-II pilot study confirmed the safety of a regimen of aspirin and ticlopidine in a subgroup of 50 of 220 patients after stenting with heparin coated stents; there was no stent thrombosis, no major bleeding complications, and a restenosis rate of $6 \%$ in this subgroup. ${ }^{15}$

The first generation of heparin coated stents will become available this year, encouraging stenting without formal anticoagulation; with optimal deployment, a single figure restenosis rate can be expected, reducing the costs of reintervention. The exact indications for elective stenting remain relatively flexible given the 
high cost of stenting and high pressure balloon dilatation over conventional angioplasty in all cases. None the less, this route to successful percutaneous coronary revascularisation has been truly revolutionary.

Division of Cardiovascular Medicine, NEAL G UREN Stanford University School of Medicine Stanford, CA 94305,

USA

NICOLAS AF CHRONOS

Andreas Grüntzig Cardiovascular Center, Assistant professor of medicine

Emory University Hospital,

Atlanta, GA 30323,

USA

1 Weintraub WS, King SB III, Douglas JS Jr, Kosinski AS. Percutaneous transluminal coronary angioplasty as a first revascularization procedure in single-, double- and triple-vessel coronary artery disease. 9 Am Coll Cardiol 1995;26:142-51.

2 Currier JW, Faxon DP. Restenosis after percutaneous transluminal coronary angioplasty: have we been aiming at the wrong target? $f$ Am Coll Cardiol 1995;25:516-20.

3 Pocock SJ, Henderson RA, Rickards AF, Hampton JR, King SB III, Hamm CW, et al. Meta-analysis of randomised trials comparing coronary angioplasty with bypass surgery. LanMeta-analysis of rand

4 Sigwart U, Puel J, Mirkovitch V, Joffre F, Kappenberger L. Intravascular stents to prevent occlusion and restenosis after transluminal angioplasty. $N$ Engl $f$ Med 1987;316:701-6.
5 Serruys PW, Strauss BH, Beatt KJ, Bertrand ME, Puel J, Rickards AF, et al. Angiographic follow-up after placement of a self-expanding coronary artery stent. $N$ Engl $f \mathrm{Med}$ 1991;324:13-7.

6 Serruys PW, de Jaegere P, Kiemeneij F, Macaya C, Rutsch W, Heyndrickx G, et al for the Benestent Study Group. A comparison of balloon expandable stent implantation with balloon angioplasty in patients with coronary artery disease. $N$ Engl f Med 1994;331:489-95.

7 Fischman DL, Leon MB, Baim D, Schatz RA, Savage MP, Penn I, et al for the Stent Restenosis Study Investigators. A randomized comparison of coronary stent placement and balloon angioplasty in the treatment of coronary artery disease. N Engl 9 Med 1994;331:496-501.

8 Schatz RA, Baim DS, Leon MB, Goldberg S, Hirshfeld NW, Cleman MW, et al. Clinical experience with Palmaz-Schatz coronary stent: initial results of a multicenter study. Circula-
and

9 George BS, Voorhess WD, Roubin GS, Fearnot NE, Pinkerton CA, Raizner AE, et al. Multicenter investigation of coronary stenting to treat acute or threatened closure after percutaneous transluminal coronary angioplasty: clinical and angiographic outcomes. $f \mathrm{Am} \mathrm{Coll}$ Cardiol 1993;22:135-43.

10 Popma J, Satler LF, Pichard AD, Kent KM, Campbell A, Chuang YC, et al. Vascular complications after balloon and new device angioplasty. Circulation 1993;88:1569-78.

11 Colombo A, Hall P, Nakamura S, Almagor Y, Maiello L, Martini G, et al. Intracoronary stenting without anticoagulation accomplished with intravascular ultrasound guidance. Circulation 1995;91:1891-7.

12 Morice MC, Zemour G, Beneviste E, Biron Y, Bourdonnec C, Faivre R, et al. Intracoronary stenting without coumadin: one month results of a French multicenter study. Cathet Cardiovasc Diag 1995;35:1-7.

13 Hall P, Nakamura S, Maiello L, Itoh A, Blengino S, Martini G, et al. A randomized comparison of combined ticlopidine and aspirin therapy versus aspirin therapy alone after parison of combined ticlopidine and aspirin therapy versus aspirin therapy alone after
successful intravascular ultrasound-guided stent implantation. Circulation 1996;93: 215-22.

14 Nakamura S, Colombo A, Gaglione S, Almagor Y, Goldberg SL, Maiello L, et al. Intracoronary ultrasound observations during stent implantation. Circulation 1994;89:2026-34.

15 Serruys PW, Emanuelsson $\mathrm{H}$, van der Giessen W, Lunn AC, Kiemeneij F, Macaya C, et al for the Benestent-II Study Group. Heparin-coated Palmaz-Schatz stents in human coronary arteries. Early outcome of the Benestent-II pilot study. Circulation 1996;93: 412-22.

\title{
Lactational amenorrhoea method for family planning
}

\author{
Provides high protection from pregnancy for the first six months after delivery
}

It has long been known that breast feeding can delay the return of fertility, but until recently the conditions under which women could rely on this phenomenon were unclear. In August 1988 an international group of scientists gathered in Bellagio, Italy, to review the scientific evidence related to the effect of breast feeding on fertility. ${ }^{12}$ In what came to be known as the "Bellagio consensus," they concluded that women who were fully or nearly fully breast feeding and amenorrhoeic had a less than $2 \%$ risk of pregnancy in the six months after delivery.

Subsequently, several groups have collected further data on risks of pregnancy among breast feeding women in relation to time after delivery and feeding patterns. ${ }^{3-7}$ Their results, including those from Ramos and colleagues reported in this week's $B M \mathcal{F}$ (p 909) ${ }^{7}$ as well as other relevant research, ${ }^{8-10}$ were reviewed in December 1995 at a second Bellagio conference. This confirmed the conclusions of the original Bellagio consensus $^{11}$ : women who are fully or nearly fully breast feeding are at very low risk of becoming pregnant in the first six months after delivery as long as they remain amenorrhoeicindeed, the observed cumulative life table rates of pregnancy at six months were less than $2 \%$. In studies that included the promotion of appropriate breast feeding practices, the percentage of women still amenorrhoeic and fully breast feeding at six months after delivery was higher than in control groups not receiving such support. ${ }^{12} 13$

From the research done to date, the experts participating in the second Bellagio conference (who included two authors of the paper by Ramos et al) also concluded that whereas amenorrhoea is an absolute requirement for ensuring a low risk of pregnancy, it might be possible to relax the requirement of full or nearly full breast feeding. ${ }^{4} 10^{14}{ }^{15}$ It may also be possible to extend the duration of use beyond six months without jeopardising effectiveness. ${ }^{1014}{ }^{15}$ Additional research is needed to establish the conditions under which these modifications to the Bellagio consensus could be made.

In 1989 a method of family planning for women was defined, based on the Bellagio consensus. It was called the lac- tational amenorrhoea method, and guidelines for its use were developed. ${ }^{16}$ These guidelines include the three criteria mentioned above-amenorrhoea, full or nearly full breast feeding, and protection limited to the first six months postpartum - all of which must be met to ensure adequate protection from an unplanned pregnancy. The guidelines include the advice that women who no longer meet these three criteria, or no longer wish to use the lactational amenorrhoea method, should immediately start to use another method of family planning if they wish to avoid pregnancy.

As well as the study by Ramos et al, several other reports have been published on the lactational amenorrhoea method, ${ }^{6}{ }^{12-18}$ but experience is still limited. Additional research is needed to determine its effectiveness and acceptability under field conditions, to evaluate the implications of running a programme of the lactational amenorrhoea method for services catering for mothers, and to assess the impact of reliance on lactational amenorrhoea on subsequent use of other family planning methods, especially among women who would not otherwise attempt family planning. As indicated earlier, the guidelines for use of lactational amenorrhoea promote the adoption of other methods of family planning as soon as the six month period of protection has ended, ${ }^{16}$ and it is therefore conceivable that using lactational amenorrhoea may increase subsequent use of contraception. $^{19}$

PAUL FA VAN LOOK Associate director

UNDP/UNFPA/WHO/World Bank Special Programme of Research,

Development and Research Training in Human Reproduction,

World Health Organisation,

1211 Geneva 27 ,

Switzerland

1 Consensus statement. Breastfeeding as a family planning method. Lancet 1988;ii:1204-5.

2 Kennedy KI, Rivera R, McNeilly AS. Consensus statement on the use of breastfeeding as a family planning method. Contraception 1989;39:477-96.

3 Kennedy KI, Visness CM. Contraceptive efficacy of lactational amenorrhoea. Lancet 1992;339:227-30. 